\title{
Role of Macrophage Oxidative Burst in the Action of Anthrax Lethal Toxin
}

\author{
Philip C. Hanna, ${ }^{*}$ Benjamin A. Kruskal, ${ }^{+}$ \\ R. Allen B. Ezekowitz, ${ }^{\dagger}$ Barry R. Bloom, ${ }^{\ddagger}$ and R. John Collier* \\ ${ }^{*}$ Department of Microbiology and Molecular Genetics and the Shipley \\ Institute of Medicine, Harvard Medical School, Boston, Massachusetts, \\ U.S.A. 'Division of Hematology and Infectious Diseases, The \\ Children's Hospital, Department of Pediatrics, Harvard Medical \\ School, Boston, Massachusetts, U.S.A. \\ ${ }^{\ddagger}$ Howard Hughes Medical Institute and Departments of Microbiology \\ and Immunology, Cell Biology, Molecular Pharmacology, and Molecular \\ Biology, Albert Einstein College of Medicine, Bronx, New York, U.S.A.
}

\begin{abstract}
Background: Major symptoms and death from systemic Bacillus anthracis infections are mediated by the action of the pathogen's lethal toxin on host macrophages. High levels of the toxin are cytolytic to macrophages, whereas low levels stimulate these cells to produce cytokines (interleukin-1 $\beta$ and tumor necrosis factor- $\alpha$ ), which induce systemic shock and death.

Materials and Methods: Experiments were performed to assess the possibility that the oxidative burst may be involved in one or both of lethal toxin's effects on macrophages. Toximediated cell lysis, superoxide anion and cytokine production were measured. Effects of antioxidants and macrophage mutations were examined.

Results: RAW264.7 murine macrophages treated with high levels of toxin released large amounts of superoxide anion, beginning at about $1 \mathrm{hr}$, which correlates with the onset of cytolysis. Cytolysis could be blocked with various exogenous antioxidants or with $\mathrm{N}$-acetyl-L-cysteine and methionine, which promote
\end{abstract}

production of the endogenous antioxidant, glutathione. Mutant murine macrophage lines deficient in production of reactive oxygen intermediates (ROIs) were relatively insensitive to the lytic effects of the toxin, whereas a line with increased oxidative burst potential showed elevated sensitivity. Also, cultured blood monocyte-derived macrophages from a patient with Chronic Granulomatous Disease, a disorder in which the phagocyte's oxidative burst is disabled, were totally resistant to toxin, in contrast to control monocytes.

Conclusions: These results imply that the cytolytic effect of the toxin is mediated by ROIs. Additionally, cytokine production and consequent pathologies showed partial dependence on macrophage ROIs. Antioxidants moderately inhibited toxin-induced cytokine production in vitro, and $\mathrm{BALB} / \mathrm{c}$ mice pretreated with $\mathrm{N}$-acetyl-L-cysteine or mepacrine showed partial protection against lethal toxin. Thus ROIs are involved in both the cytolytic action of anthrax lethal toxin and the overall pathologic process in vivo.

\section{INTRODUCTION}

A key component of the host's ability to survive bacterial challenge is the innate capacity of phagocytes to ingest and destroy the invading

Address correspondence and reprint requests to: R. John Collier, Department of Microbiology and Molecular Genetics, Harvard Medical School, 200 Longwood Avenue,

D1-502, Boston, MA 02115, U.S.A. organism. Phagocytes, neutrophils and monocytes/macrophages (M $\phi \mathrm{s})$, maintain an extensive portfolio of mechanisms for killing phagocytosed organisms, which include: extremes of $\mathrm{pH}$, lysozyme secretion, release of hydrolytic enzymes, membrane-damaging defensins and other small cationic proteins, and the unique ability to generate large amounts of reactive oxy- 
gen and nitrogen intermediates (ROIs and RNIs, respectively). Some of these agents may be toxic to the phagocytes, which must therefore tightly regulate their production and/or restrict them to subcellular locales where their effects can be tolerated. The potential exists, therefore, for pathogens to divert these killing mechanisms toward phagocytes themselves.

Anthrax has historically been a useful model for studying infectious diseases and host-parasite relationships $(1,2)$. In particular, Bacillus anthracis, the etiologic agent, has played an important role in elucidating $M \phi$-bacterium interactions. Metchnikoff (3), using transparent tissues of living animals attached to his microscope stage, employed the anthrax bacillus to demonstrate that large blood cells left the circulatory system (diapedesis), migrated toward a site of infection, and ingested the invading pathogens. He named these cells macrophages. Modern studies have further linked $B$. anthracis and its virulence factors to the $M \phi$, and these interactions are now known to be intimately involved in the clinical manifestations of the disease.

Anthrax in humans, and most other animals, is initiated by introduction of $B$. anthracis spores into the body by penetration of the epidermis, the gut, or the respiratory epithelia (4). After spore germination, the bacteria multiply and may spread to the regional lymph nodes and from there to the blood stream where they can reach $>10^{8} / \mathrm{ml}$. Systemic anthrax is nearly always fatal, with nonspecific, shock-like symptoms. Of particular note is the suddenness of the fatal shock; in animals, the first overt symptom is often death itself (4).

Virulence of $B$. anthracis depends upon three plasmid-encoded factors: an antiphagocytic polyD-glutamic acid capsule and two protein toxins (5). Edema toxin (EdTx) is believed to be responsible for the edema seen in the cutaneous form of anthrax and is composed of two noncovalently linked proteins, protective antigen (PA, $83 \mathrm{kD}$ ) and edema factor (EF, $88 \mathrm{kD}$ ). Lethal toxin (LeTx), the central effector of shock and death during systemic anthrax, is also comprised of two proteins, PA and lethal factor $(\mathrm{LF}, 89 \mathrm{kD})$. PA, the protein in common, serves to bind either EF or LF to cell surface receptors and mediate their transfer into the cytoplasm. There, EF functions as a $\mathrm{Ca}^{++}$-calmodulin-dependent adenylate cyclase (6). The biochemical action of LF is unknown, but a recent report indicates that LF shares limited sequence homology to active site regions of a family of $\mathrm{Zn}^{++}$-dependent proteases (7).
Injection of LeTx mimics symptoms of systemic anthrax in test animals, and LeTx-deficient strains of $B$. anthracis are highly attenuated (8-9). Although most cell types bind and internalize the toxin, only M $\phi$ s are killed (10). At high toxin doses, these cells are lysed within 1-2 $\mathrm{hr}$ in vitro. We found that mice depleted of $M \phi s$ are resistant to LeTx, and these mice can be resensitized by injecting cultured $M \phi s$ but not other types of cells (11). At low concentrations, LeTx is not cytolytic but stimulates cytokine production in cultured $M \phi$ s. Furthermore, passive immunity to Il- $1 \beta$ and TNF $\alpha$ protects mice from toxin challenge, implying that these cytokines mediate animal death (11). Thus it is clear that the $M \phi$ plays a central role in anthrax LeTx action, although the underlying biochemistry of the effects seen in these cells is not yet understood.

We recently described a cascade of biochemical and physiological changes in LeTx-challenged $M \phi s$, which culminates in cytolysis (12). That study implicated an early increase in plasma membrane permeability to $\mathrm{Na}^{+}$and $\mathrm{K}^{+}$, causing misregulated cellular colloidosmotic equilibrium, influx of water into the cell, hydrolysis of ATP, and eventual $\mathrm{Ca}^{++}$influx (and serious $\mathrm{Ca}^{++}$ induced toxicities). These initial insults triggered downstream effects, including cessation of virtually all macromolecular synthesis, changes in cell morphology, and generalized membrane rupture. These events resemble, at least superficially, those reported for cells exposed to oxidants. We therefore hypothesized that damaging ROIs might play a role in the responses of $M \phi$ s to the LeTx. The current study explores this possibility.

\section{MATERIALS AND METHODS}

\section{Anthrax Toxin Preparation}

B. anthracis strain Sterne is nonencapsulated and was maintained as spore stocks. Cultures were grown in defined RM toxin-production medium (13). Culture supernatants were sterilized by passage through a $0.22 \mu \mathrm{m}$ filter (Millipore, Bedford, MA, U.S.A.) and concentrated to 11 with the Minitan Ultrafiltration System (Millipore). Ammonium sulfate was added to $75 \%$, and the protein pellet was collected and suspended in 20 $\mathrm{mM}$ tris(hydroxymethyl)aminomethane (Tris)$\mathrm{HCl}, \mathrm{pH} \mathrm{8.0}$, and dialyzed extensively against the same buffer. An efficient one-step purification was performed by FPLC MonoQ anion exchange (Pharmacia, Piscataway, NJ, U.S.A.) with a 20 
$\mathrm{mM}$ Tris- $\mathrm{HCl}, \mathrm{pH} 8.0$, buffer and linear $0-400$ $\mathrm{mM} \mathrm{NaCl}$ gradient elution over $40 \mathrm{~min}$. PA eluted at $130-140 \mathrm{mM} \mathrm{NaCl}$, EF at 150-175 $\mathrm{mM}$, and LF at 250-270 mM. PA, EF, and LF were each determined to be $90-95 \%$ pure by sodium dodecyl sulfate-polyacrylamide gel electrophoresis (SDS-PAGE) analysis, and none of the toxin components alone affected cells. For cytotoxicity assays, unless otherwise noted, the final concentration of lethal toxin was PA $=0.1$ $\mu \mathrm{g} / \mathrm{ml} ; \mathrm{LF}=0.1 \mu \mathrm{g} / \mathrm{ml}$.

\section{Cell Culture}

Murine macrophage lines RAW 264.7 (ATCC TIB-71), J774 (ATCC TIB-67), and IC-21 (ATCC TIB-186) were obtained from the American Type Culture Collection (Rockville, MD, U.S.A.) and were maintained in minimal essential medium (MEM) supplemented with Earl's salts, $10 \%$ fetal calf serum (FCS), penecillin $(200 \mu \mathrm{g} / \mathrm{ml})$, streptomycin $(100 \mu \mathrm{g} / \mathrm{ml})$, and $10 \mathrm{mM} \mathrm{N}$-2-hydroxyethylpiperazine- $\mathrm{N}^{\prime}$-2-ethanesulfonic acid (HEPES), $\mathrm{pH}$ 7.0. Murine macrophage lines J774.16, C3C, and D9 are originally derived from the J774 parent (14-15) and maintained in Dulbecco's modified Eagle's medium (DMEM) containing high glucose $(4,500 \mathrm{mg} / \mathrm{l})$ supplemented with $10 \%$ FCS, $1 \%$ nonessential amino acids, $5 \%$ NCTC 109, HEPES, and antibiotics as above. Cells were grown in a humidified atmosphere of $5 \%$ carbon dioxide and $95 \%$ air at $37^{\circ} \mathrm{C}$ in 75 $\mathrm{cm}^{2}$ plastic flasks (Corning, Corning, NY, U.S.A.). For cytotoxicity experiments, cells were harvested by scraping with a rubber policeman, plated at a density of $5 \times 10^{5}$ cells $/ \mathrm{ml}$ in $2 \mathrm{~cm}^{2}$ 24-well dishes (Corning), and grown for 36-48 hr to approximately $80-90 \%$ confluence (1-2 $\times$ $10^{6}$ cells/well). For superoxide anion production assays, cells were gently removed from dishes by incubation in sterile medium containing $1.5 \%$ lidocaine at $37^{\circ} \mathrm{C}$ for $5 \mathrm{~min}$. Cells were immediately pelleted and washed twice in lidocaine-free medium and suspended in medium in siliconized $50 \mathrm{ml}$ plastic centrifuge tubes at a concentration of $1 \times 10^{7} / \mathrm{ml}$ at $37^{\circ} \mathrm{C}$ with occasional swirling.

Human blood monocytes were purified from $50 \mathrm{ml}$ of blood by dilution 1:1 with sterile phosphate-buffered saline (PBS) and maintained at $22^{\circ} \mathrm{C}$ for $1 \mathrm{hr}$. Diluted blood was then layered onto an equal volume of HISTOPAQUE-1119 (Sigma, St. Louis, MO, U.S.A.) in $50 \mathrm{ml}$ centrifuge tubes and spun $700 \times \mathrm{g}$ for $30 \mathrm{~min}$. The top layer (serum) was removed, heat-inactivated, and saved for medium completion (DMEM, 10\% autologous serum, antibiotics, and HEPES as above). The mononuclear cell layer was diluted 1:2 in sterile PBS and spun for $5 \mathrm{~min}$ at $200 \times \mathrm{g}$ to remove any red cells. This was repeated for a total of three washes. Cells were plated in completed medium at a density of $1 \times 10^{6}$ cells $/ \mathrm{ml}$ in 24-well dishes and incubated (as above) for 2 days to allow for monocyte differentiation into macrophages before assay for LeTx cytotoxicity.

\section{Measurement of Superoxide Anion Production}

$\mathrm{O}_{2}$ - was measured by the SOD-inhibitable reduction of ferricytochrome c $(15,16)$. Briefly, macrophages $\left(1 \times 10^{7} / \mathrm{ml}\right)$ were kept suspended in $50 \mathrm{ml}$ centrifuge tubes at $37^{\circ} \mathrm{C}$ in the presence of $160 \mu \mathrm{M}$ cytochrome c (type III; Sigma) in the presence or absence of LeTx $(\mathrm{PA}=0.1 \mu \mathrm{g} / \mathrm{ml}, \mathrm{LF}$ $=0.1 \mu \mathrm{g} / \mathrm{ml}$ ). Reference samples also contained $75 \mu \mathrm{g} / \mathrm{ml}$ of SOD (Sigma). At the indicated times $(0-8 \mathrm{hr}), 1 \mathrm{ml}$ samples were gently removed, placed into cuvettes, and analyzed in a Beckamn DU-640 spectrophotometer. Reduction of cytochrome c was measured at $550 \mathrm{~nm}$. The amount of SOD-inhibitable $\mathrm{O}_{2}$ - production was calculated on the basis of an extinction coefficient of cytochrome c of $21 \mathrm{mM}^{-1} \mathrm{~cm}^{-1}$ and is expressed as a function of time in nanomoles $/ 10^{7}$ cells.

\section{Cytotoxicity Assays}

For cell-rupture studies measuring the efflux of ${ }^{51} \mathrm{Cr}$ from cells, nearly confluent monolayers of cells were prepared as described above and incubated overnight with the cytoplasmic marker $\mathrm{Na}_{2}{ }^{51} \mathrm{CrO}_{4}(1 \mu \mathrm{Ci} / \mathrm{ml}, 1 \mathrm{Ci}=37 \mathrm{GBq}$; Dupont/ NEN, Boston, MA, U.S.A.) $(11,12)$. Cultures were then washed twice and challenged at $37^{\circ} \mathrm{C}$ with LeTx or controls in the presence or absence of the indicated antioxidants. After $4 \mathrm{hr}$ of challenge, culture supernatant was gently removed and counted. The amount of radioactivity released from the cells was calculated with the formula: percent maximal release $=100 \times$ (toxin-induced release - spontaneous release)/ (maximal release - spontaneous release).

Spontaneous release represents radiolabel released into the medium without toxin challenge. The maximal release of cytoplasmic label represents the total available cytoplasmic radioactivity at the end of radiolabeling (i.e., before challenge) and was determined after cell membrane rupture by the addition of $1 \mathrm{ml}$ of $1 \%$ Triton X-100 to each well. In these studies, max- 
imal release of $\mathrm{Cr}^{51}$ was approximately 12,000 $\mathrm{cpm} /$ well, and spontaneous release was approximately $900 \mathrm{cpm} /$ well.

\section{Measurement of Cytokine Production}

Macrophage production of TNF- $\alpha$ and IL- $1 \beta$, as a function of LeTx-challenge $(6 \mathrm{hr}$ incubation in the presence of the indicated antioxidants), were performed by ELISA (Genzyme, Boston, MA, U.S.A.) as specified by the manufacturer, and presented values represent the sum of extracellular plus intracellular cytokine pools (11).

\section{In Vivo Lethality Assays}

Six-month-old BALB/c mice (approximately l:1, male:female) were lightly anesthetized and challenged with the indicated amounts of anthrax LeTx via tail vein injections as described previously (11). Nearly simultaneous injection of the indicated antioxidant was performed at a seperate tail vein site.

\section{Other Materials and Methods}

Unless otherwise indicated, all chemicals were purchased from Sigma Chemicals. Protein determinations were performed with Coomassie protein assay reagent (Pierce, Rockford, IL, U.S.A.) with bovine serum albumin as a standard.

\section{RESULTS}

Production of microbicidal ROIs during oxidative burst is initiated and regulated by the NADPH oxidase complex. The primary species of ROI, superoxide anion $\left(\mathrm{O}_{2}{ }^{-}\right)$, is generated by the single electron reduction of molecular oxygen. $\mathrm{O}_{2}{ }^{-}$ can then be reduced further to form other reactive species, such as singlet oxygen $\left(\mathrm{O}_{2}{ }^{1}\right)$, hydrogen peroxide $\left(\mathrm{H}_{2} \mathrm{O}_{2}\right)$, and hydroxyl radical $(\cdot \mathrm{OH})$. Additionally, $\mathrm{H}_{2} \mathrm{O}_{2}$ can be halogenated to form the toxic agent hypochlorate $\left({ }^{-} \mathrm{OCl}\right)$. These powerful oxidants are known to disrupt membrane integrity, intermediate metabolism, and protein functions. The fact that similar disruptions are seen in macrophages treated with anthrax LeTx led us to ask if ROIs play a role in LeTx action. We have applied three experimental approaches to this question: direct measurement of $\mathrm{O}_{2}{ }^{-}$production by toxin-challenged $M \phi s$; tests of exogenous and endogenous antioxidants as protective agents against toxin; and determination of
LeTx-sensitivity of a variety of murine and human macrophage cell lines that are altered in oxidative burst potential.

A cultured murine RAW264.7 macrophage line was tested for $\mathrm{O}_{2}{ }^{-}$expression as a function of time after addition of cytolytic concentrations of toxin (Fig. 1). Production of $\mathrm{O}_{2}{ }^{-}$as measured by cytochrome c reduction was first observed approximately $\mathrm{l} \mathrm{hr}$ after toxin addition, which coincided with the onset of cytolysis. Both PA and LF were required for these effects. Maximal stimulation of the oxidative burst by LeTx was approximately two to three times that observed with PMA, a potent stimulator of the respiratory burst $\left(220 \mathrm{nmol} \mathrm{O}_{2}{ }^{-} / 10^{7}\right.$ cells in $2 \mathrm{hr}$ for LeTx versus $90 \mathrm{nmol} \mathrm{O}_{2}{ }^{-} / 10^{7}$ cells for PMA). Presumably the binding, processing, internalization, and putative enzymatic steps account for the lag period seen with the toxin.

To assess the possibility that the high levels of ROIs induced by LeTx contribute to lysis, several types of potential protective agents were added to the challenge medium. Data in Fig. 2 indicate that exogenous cell-permeable antioxidants protect $M \phi$ s from LeTx in a dose-dependent manner. These include reducing agents (BME, DTT), solvents that can trap free radicals (ethanol, DMSO), and vitamins (ascorbate and $\alpha$-tocopherol). Oxidized DTT conferred no protective effect and served as a control. Mepacrine, an anticancer drug that inhibits phospholipases and also acts as an oxygen scavenger, was also protective. It is probably the latter property that gives mepacrine its protective capabilities, since we found that several other classes of phospholipase inhibitors were not protective (e.g., 7,7 - dimethyl - (5Z,8Z) - eicosadienoic acid; dimethyl- DL - 2,3 - distearoly - oxypropyl - $2^{\prime}$ hydroxyethyl - ammonium acetate; O-tricyclo [5.2.1.0(2.6)]DEC - 9 - YL - dithiocarbonate; antiinflammatory peptide 2 ; hexadecylphosphocholine; data not shown).

Two control experiments suggest that these agents exert their protective effects at a step subsequent to toxin internalization. (1) Antioxidant concentrations that gave $75-90 \%$ protection from LeTx had virtually no effect on EdTx action (Table 1). Since LeTx and EdTx are believed to enter cells by the same pathway (18), this implies that the entry process is unaffected. (2) The protective effects of BME, DTT, and EtOH were rapidly reversed (within $30 \mathrm{~min}$ ) after removing the inhibitor from the medium (data not shown). Removal of dimethylsulfoxide (DMSO), mepacrine, and vitamins $C$ and $E$ did not restore cy- 

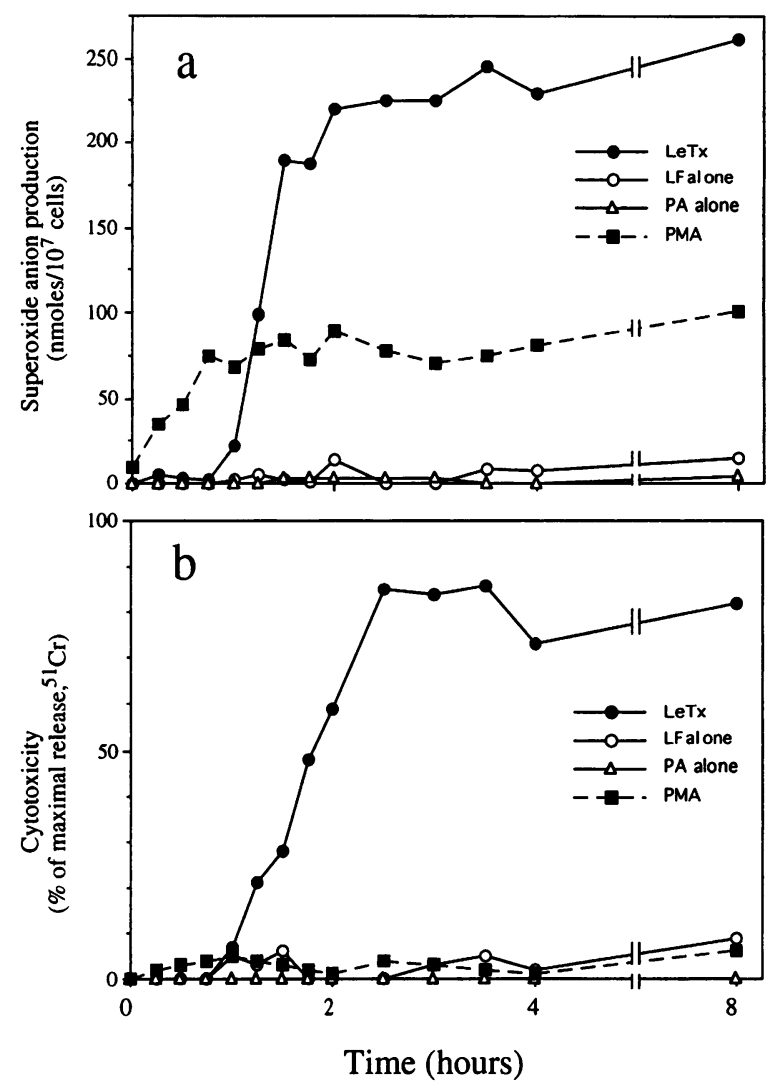

FIG. 1. Time course of lethal toxin-induced $\mathrm{O}_{2}{ }^{-}$production and lysis

$\mathrm{M} \phi$ production of $\mathrm{O}_{2}^{-}$(a) and cytotoxicity (b) were compared after exposure to LeTx or controls. RAW 264.7 cells were grown and prepared as described. Superoxide anion production was determined by monitoring changes in Absorbance ${ }_{550}$ due to cytochrome c reduction. Cells to be monitored for cytotoxicity were loaded with $\mathrm{Na}_{2}{ }^{51} \mathrm{CrO}_{4}$ for $16 \mathrm{hr}$, and washed twice before challenge. ${ }^{51} \mathrm{Cr}$ release was normalized for spontaneous leakage $\left(<1,000 \mathrm{cpm} / 10^{6}\right.$ cells) and plotted as the percentage of total radioactivity in the cells (approximately $12,000 \mathrm{cpm} / 10^{6}$ cells). Challenge concentrations were: $\mathrm{PA}=0.1 \mu \mathrm{g} /$ $\mathrm{ml}, \mathrm{LF}=0.1 \mu \mathrm{g} / \mathrm{ml}, \mathrm{PMA}=10 \mathrm{ng} / \mathrm{ml}$. Experiments measuring $\mathrm{O}_{2}{ }^{-}$production and cytotoxicity were run in parallel (triplicate samples); with three experimental series run for both ${ }^{51} \mathrm{Cr}$ and $\mathrm{O}_{2}{ }^{-}$production. SEM values were $<13 \%$ of the indicated value $\mathrm{O}_{2}{ }^{-}$ measurement) and $<5 \%$ of the indicated value $\left({ }^{51} \mathrm{Cr}\right.$ assay) $(n=3)$. Higher doses of PMA (highest dose $=$ $0.1 \mu \mathrm{g} / \mathrm{ml}$ ) did not significantly increase $\mathrm{O}_{2}{ }^{-}$production and did not induce cytotoxicity (data not shown).
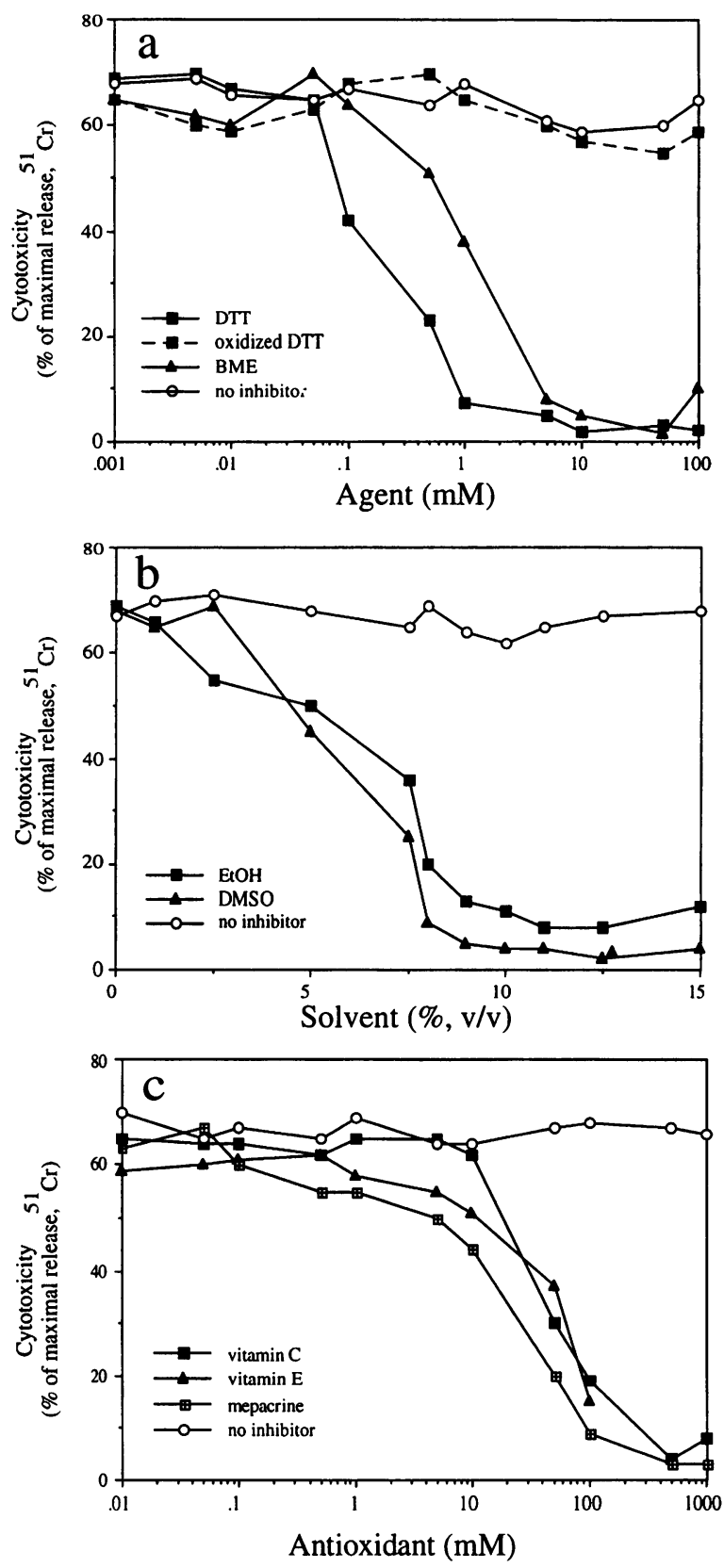

FIG. 2. Exogenous antioxidants protect $M \phi s$ from lethal toxin

RAW 264.7 M $\phi$ cultures were prepared as described and challenged with lethal toxin (PA $=0.1 \mu \mathrm{g} / \mathrm{ml}$, $\mathrm{LF}=0.1 \mu \mathrm{g} / \mathrm{ml}$ ) in the presence of the indicated concentrations of antioxidants: reducing agents (a), organic solvents (b), or dietary vitamins (c). Protection from the cytolytic effects of the LeTx was scored using the ${ }^{51} \mathrm{Cr}$ release assay described in Materials and Methods. Specific release of approximately $65 \%$ of the available ${ }^{51} \mathrm{Cr}$ from cells represents $100 \% \mathrm{cy}-$ totoxicity due to LeTx. Antioxidants alone, at the given concentrations, were not cytotoxic to $\mathrm{M} \phi \mathrm{cul}$ tures. Experiments were run in duplicate with two experimental series each. SEM values for each data point was $<9 \%$ of the indicated value. 
TABLE 1. Effects of antioxidants on edema toxin and lethal toxin actions in RAW264.7 M申 cultures

\begin{tabular}{lccc}
\hline & & \multicolumn{2}{c}{$\begin{array}{c}\text { Percent of } \\
\text { Initial Toxin } \\
\text { Activity }\end{array}$} \\
\cline { 3 - 4 } Antioxidant & Concentration & EdTx $^{a}$ & LeTx $^{b}$ \\
\hline None & - & $100 \%$ & $100 \%$ \\
DTT & $10 \mathrm{mM}$ & 91 & 3 \\
BME & $10 \mathrm{mM}$ & 94 & 6 \\
EtOH & $10 \%(\mathrm{v} / \mathrm{v})$ & 99 & 12 \\
DMSO & $10 \%(\mathrm{v} / \mathrm{v})$ & 108 & 7 \\
ascorbate & $100 \mathrm{mM}$ & 95 & 21 \\
$\alpha$-tocopherol & $100 \mathrm{mM}$ & 90 & 18 \\
mepacrine & $100 \mathrm{mM}$ & 88 & 10 \\
NAC & & 99 & 5 \\
met $^{c}$ & $50 \mathrm{mM}$ & 103 & 9 \\
& $100 \mathrm{mM}$ & &
\end{tabular}

${ }^{a} E \mathrm{dTX}$-induced increase of cellular cAMP was determined by radioimmunoassay, using a cAMP scintillation proximity assay. $100 \%$ activity is defined as the amount of cAMP in cells $(950 \mathrm{fmol} / \mu \mathrm{g}$ protein) $45 \mathrm{~min}$ after addition of toxin (0.1 $\mu \mathrm{g} \mathrm{PA}+0.1 \mu \mathrm{g} \mathrm{EF} / \mathrm{ml}$ ), after normalization for cAMP present in untreated cells.

${ }^{b}$ LeTx-induced cytotoxicity was measured by release of ${ }^{51} \mathrm{Cr}$ from prelabeled cells (see Fig. 1 legend).

'NAC and met were preincubated with cells for $16 \mathrm{hr}$ before toxin challenge (see Fig. 3).

totoxicity, presumably because they are retained within cells.

All cells, including $M \phi s$, contain $\mathrm{mM}$ concentrations of glutathione (GSH, $\gamma$-glu-cys-gly), which serves (among other purposes) to counteract oxidants (19). The thiol group on the Cys residue of GSH acts as an endogenous scavenger, and in the process, GSH is oxidized to a GS-SG dimer (or a GS-S-protein adduct). GS-SG is then reduced to regenerate GSH or exported from the cell via an ATP-driven pump. When oxidants overload GSH's capacity for reductive detoxification, cell damage occurs. It is possible to increase GSH concentrations several-fold by supplementing cells with certain metabolic precursors, $\mathrm{N}$ acetyl-L-cysteine, or methionine. We therefore tested M $\phi$ s for LeTx sensitivity after preincubation with these precursors or with the other normal amino acids as controls. As shown in Fig. 3, both NAC and Met provided strong protective effects against LeTx (Fig. 3a) whereas glycine did not. Among the other (20) amino acids tested,
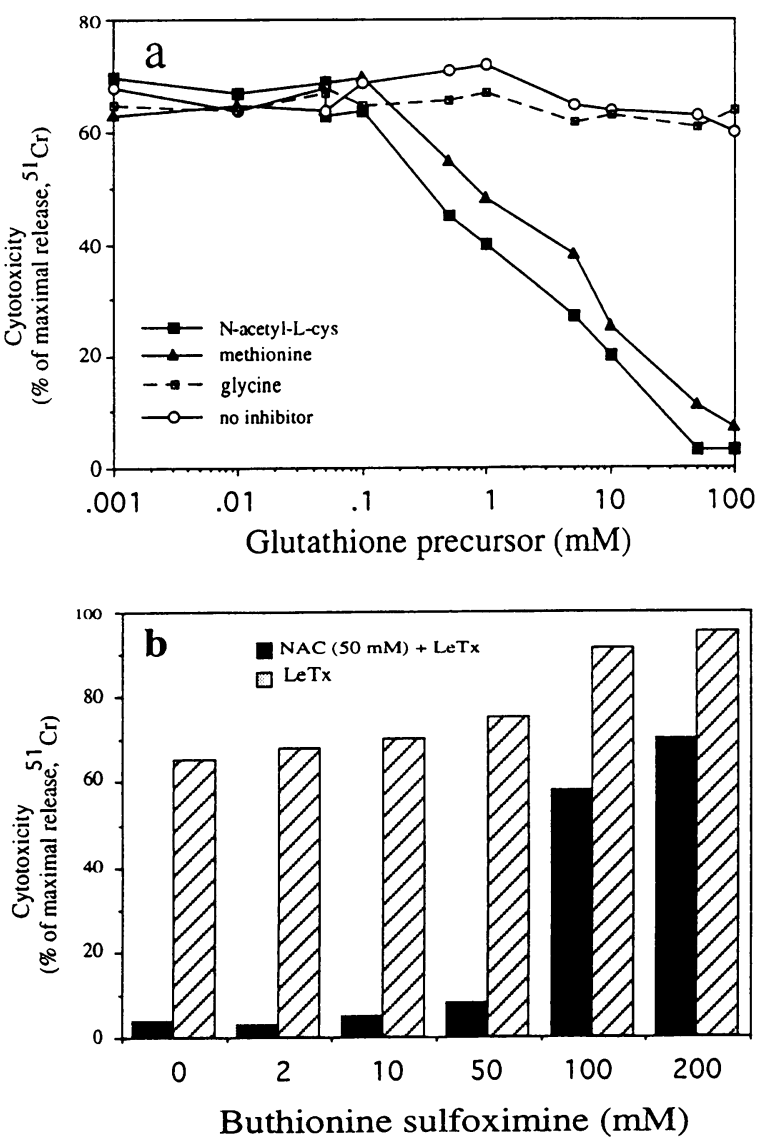

FIG. 3. Glutathione precursors protect $M \phi s$ from lethal toxin

(A) Cellular levels of glutathione, an endogenous antioxidant, were increased by preincubating RAW 264.7 cultures with the indicated concentrations of precursor (N-acetyl-L-cysteine or methionine) for 16 hr prior to LeTx challenge (PA $=0.1 \mu \mathrm{g} / \mathrm{ml}$, LF $=$ $0.1 \mu \mathrm{g} / \mathrm{ml})$. Cytotoxicity was scored using the ${ }^{51} \mathrm{Cr}$ release assay described in Materials and Methods. Control amino acids did not protect $M \phi$ s from LeTx challenge. Experiments were run in triplicate with two experimental series. SEM values for each data point were $<11 \%$ of the indicated value. (B) Preventing precursor incorporation into glutathione by buthionine sulfoximine (BSO), a competitive inhibitor of glutathione synthetase, blocks the protective ability of $\mathrm{N}$-acetyl-L-cysteine. $\mathrm{M} \phi$ cultures were preincubated in the presence or absence of the $\mathrm{N}$-acetyl-L-cysteine $(50 \mathrm{mM})$, in the presence of the indicated amounts of BSO (0-200 mM) for $16 \mathrm{hr}$ prior to LeTx challenge $(\mathrm{PA}=0.1 \mu \mathrm{g} / \mathrm{ml}, \mathrm{LF}=0.1$ $\mu \mathrm{g} / \mathrm{ml})$. LeTx toxicity was assayed by ${ }^{51} \mathrm{Cr}$-release as previously described. Experiments were run in duplicate with two experimental series. SEM values for each point were $<12 \%$ of the indicated value. 
TABLE 2. Correlation of $M \phi$ sensitivity to LeTx with ability to mount an oxidative burst

\begin{tabular}{|c|c|c|c|c|}
\hline & \multicolumn{2}{|c|}{$\underset{\text { Production }^{a}}{\text { PMA-Induced } \mathrm{O}_{2}^{-}}$} & \multicolumn{2}{|c|}{ LeTx-Cytotoxicity ${ }^{b}$} \\
\hline & $\begin{array}{l}\left(\mathrm{nmol} / \mathbf{1 0}^{7}\right. \\
\text { cells/hr) }\end{array}$ & $\begin{array}{l}\text { (Relative } \\
\text { Activity) }\end{array}$ & $\begin{array}{l}\text { (\% of Maximal } \\
\text { Release) }\end{array}$ & $\begin{array}{l}\text { (Relative } \\
\text { Activity) }\end{array}$ \\
\hline \multicolumn{5}{|l|}{ A. Murine Lines } \\
\hline$J 774$ & 21 & $100 \%$ & 60 & $100 \%$ \\
\hline$J 774.16$ & 34 & 162 & 69 & 115 \\
\hline $3 C 3$ & 14 & 67 & 52 & 87 \\
\hline$D-9$ & 11 & 52 & 45 & 75 \\
\hline$R A W 264.7$ & 75 & 357 & 79 & 134 \\
\hline$I C-21$ & $<1$ & $<5$ & 0 & 0 \\
\hline \multicolumn{5}{|c|}{ B. $1^{\circ}$ Human Monocytes } \\
\hline$L N$ (CGD Patient) & 0 & 0 & $<1$ & $<2$ \\
\hline PH (Control) & 23 & 109 & 44 & 73 \\
\hline
\end{tabular}

only glutamic acid showed any protective effect and this was weak (data not shown). While both Gly and Glu are precursors of GSH they are normally not rate limiting in its synthesis. The hypothesis that NAC and Met protected cells by stimulating GSH synthesis is supported by the finding that buthionine sulfoximine (BSO) (20), a competitive inhibitor of $\gamma$-glu-cys synthetase, relieved the protective effects of these precursors against LeTx action (Fig. 3b). Data in Fig. 3b also indicate that shrinking the normal GSH pools by BSO-pretreatment increases $M \phi$ susceptibility to LeTx. Neither NAC nor Met significantly reduced EdTx activity (Table 1), implying that the protective effects of these amino acids occurred only after toxin entry into cells.

To determine if hyperstimulation of the NADPH oxidase system is ultimately responsible for LeTx-induced lysis, we tested various $\mathbf{M \phi}$ lines differing in capability to generate oxidants. The transformed murine peritoneal $\mathrm{M} \phi$ line, J774, was chosen as the standard (sensitivity = $100 \%$ ). Although the J774 line is somewhat attenuated in ROI production relative to freshly prepared murine monocyte cultures, this cell line is well characterized and there are ROI mutants derived from it that have increased or decreased
ROI potentials. For example, the J774.16 mutant is more active and the $3 \mathrm{C} 3$ and $\mathrm{D} 9$ mutants are less active in ROI production (Table 2). Lines IC-21 and RAW264.7, which are not derived from J774, are also well characterized in this regard, IC-21 being totally unable and RAW264.7 fully able to mount a ROI response. Results presented in Table 2 indicate a strong correlation between toxin sensitivity and the ability to generate ROIs. The remarkable insensitivity of IC-21 (21) cells to LeTx is apparently due to the well-documented inability of these cells to generate superoxide anion (22).

The link between ROIs and LeTx cytotoxicity was further investigated in cultured primary human $M \phi^{\prime}$ s. Blood monocyte cultures from an adult patient with a rare autosomal recessive form of chronic granulomatous disease was tested (23). The patient has a missense mutation and a heterozygous deletion at $16 \mathrm{p} 24$ that encompasses the p22 phox gene encoding the $22 \mathrm{kD}$ light chain subunit of cytochrome b558. The failure to assemble the $b$ cytochrome of the NADPH oxidase complex renders this patient's phagocytes unable to generate reactive oxygen intermediates. Monocyte cultures from this CGD patient proved to be entirely resistant to LeTx, 

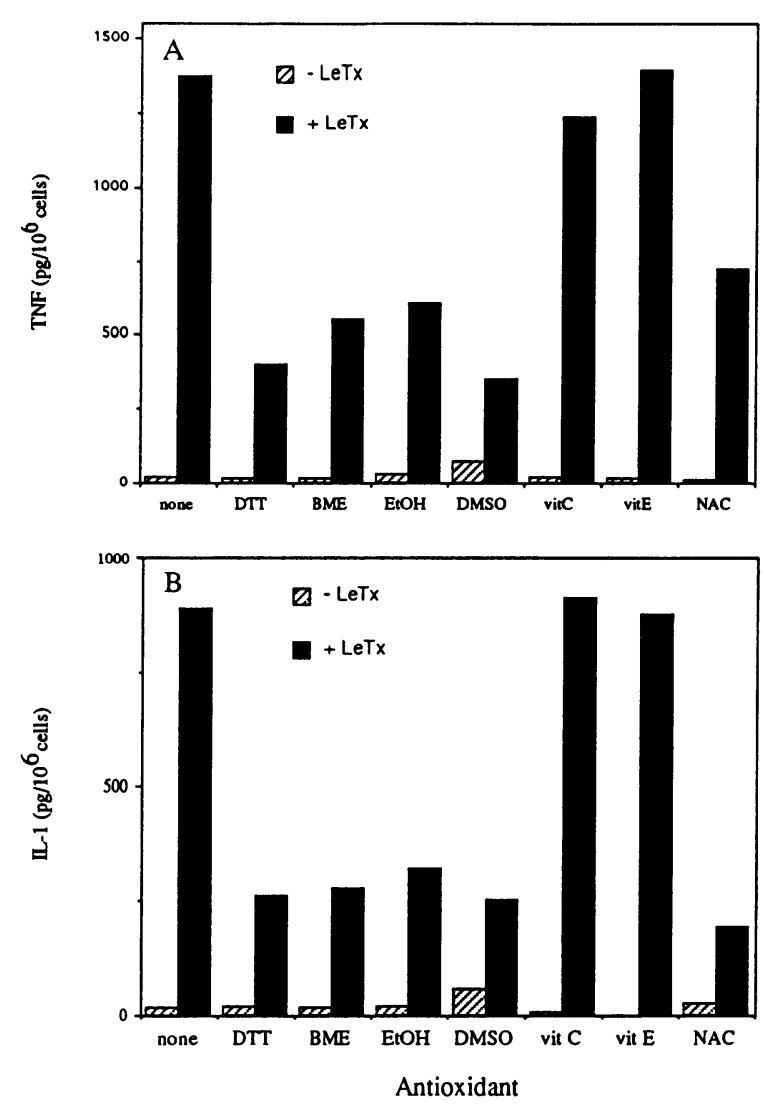

FIG. 4. Antioxidants decrease toxin-induced expression of TNF $\alpha$ and IL-1 $\beta$

RAW 264.7 cultures were prepared as described in Materials and Methods and challenged with sublytic amount of LeTx known to induce a large cytokine response $\left(\mathrm{PA}=0.1 \mu \mathrm{g} / \mathrm{ml}, \mathrm{LF}=10^{-6} \mu \mathrm{g} / \mathrm{ml}\right.$ ) in the presence of various antioxidants: DTT and BME (10 $\mathrm{mM})$, ethanol and DMSO $(10 \%, \mathrm{v} / \mathrm{v})$, vitamins C and $\mathrm{E}$ and mepacrine (100 $\mathrm{mM})$. N-acetyl-L-cysteine $(50 \mathrm{mM})$ was preincubated with $\mathrm{M} \phi$ cells for $16 \mathrm{hr}$ prior to LeTx challenge to allow for incorporation into glutathione. After $6 \mathrm{hr}$ in toxin-containing media, cells were lysed with $0.1 \%$ Triton $X-100$ and total (cellular plus extracellular) TNF $\alpha$ (a) and IL-1 $\beta$ (b) concentrations were determined by ELISA. Experiments were run in duplicate with two experimental series. SEM values for each point were $<18 \%$ of the indicated value.

while control human monocytes were susceptible (Table 2 ).

Evidence that $M \phi$ lysis by LeTx is dependent on ROIs raises the question of the possible involvement of the other $M \phi$-derived free radical gas, nitric oxide (NO), and other RNIs. These compounds, like the ROIs, are inducible, microbicidal and, at high concentrations, toxic to host cells. Several lines of evidence suggest that RNIs are unlikely to be involved, however. First, lysis of M $\phi$ s by LeTx occurs within 1-2 hr, while high-level NO production is reported to occur only 10-12 hr after induction. Second, we found that neither NMMA nor aminoguanidine, both of which are inhibitors of NO synthetases, protected $M \phi$ s from the toxin (data not shown). Lastly, the cell line IC-21, a well characterized M $\phi$ model for inducible NO-mediated killing of pathogens (22), is entirely insensitive to the effects of LeTx. Although these findings make it unlikely that NO is directly responsible for cell killing, possible regulatory roles for low-level RNI expression have not been ruled out.

In an earlier study (11) we showed: (1) that macrophages are required for the lethal action of LeTx in mice; (2) that sublytic doses of LeTx (orders of magnitude lower than those required for cell lysis) induce production of large amounts of TNF $\alpha$ and IL-1 $\beta$ in vitro; and (3) that passive immunity to these cytokines enabled mice to survive LeTx challenge. We concluded that the $M \phi$-cytokine response is central to the lethal shock symptoms of anthrax. It is therefore important to discover if ROIs play a role in regulation of $M \phi$ cytokine expression and to determine whether or not scavengers of free radical oxygen protect animals from LeTx. The effect of various oxygen scavengers on toxin-induced cytokine production by cultured $M \phi s$ is shown in Fig. 4. The results indicate that DTT, BME, EtOH, DMSO, and NAC significantly reduce the amount of TNF $\alpha$ and IL- $1 \beta$ generated in response to low-dose LeTx treatment while vitamins $C$ and $E$ appear to have little, if any, effect.

Those antioxidants that are relatively nontoxic to animals were also tested in vivo. Sixmonth-old BALB/c mice were injected with $\mathrm{N}$-acetyl-L-cysteine, mepacrine or vitamin $\mathrm{C}$ simultaneously to LeTx challenge. Although none of these compounds fully protected mice from high toxin doses, a significant reduction in mortality, both in terms of increased survival and increased time to death, was observed in mice receiving $\mathrm{N}$-acetyl-L-cysteine or mepacrine at intermediate and low toxin doses (Table 3). No protection was observed with ascorbate. These data (Fig. 4, Table 3) suggest that certain antioxidants may neutralize the regulatory effects of ROIs, thus lowering cytokine production by host $M \phi ' s$ and reducing the fatal pathologies associated with anthrax lethal toxin in the victim. Why all antioxidants were not equally protective is unclear but may involve differences in metabolic breakdown rates. 
TABLE 3. Effect of antioxidants on lethal toxin-induced mortality of mice

\begin{tabular}{|c|c|c|c|c|c|c|c|c|c|c|}
\hline \multirow[b]{2}{*}{ Toxin Dose } & \multirow[b]{2}{*}{ Antioxidant $^{d}$} & \multicolumn{9}{|c|}{ Mice Surviving $(n=8)$} \\
\hline & & $\begin{array}{c}\text { Day } \\
0\end{array}$ & $\begin{array}{c}\text { Day } \\
1\end{array}$ & $\begin{array}{c}\text { Day } \\
\mathbf{2}\end{array}$ & $\begin{array}{c}\text { Day } \\
3\end{array}$ & $\begin{array}{c}\text { Day } \\
4\end{array}$ & $\begin{array}{c}\text { Day } \\
5\end{array}$ & $\begin{array}{c}\text { Day } \\
6\end{array}$ & $\begin{array}{c}\text { Day } \\
7\end{array}$ & $\begin{array}{c}\text { Day } \\
14^{e}\end{array}$ \\
\hline \multirow[t]{4}{*}{ High Dose $\mathrm{e}^{a}$} & None & 8 & 3 & 1 & 0 & - & - & - & - & 0 \\
\hline & NAC & 8 & 7 & 5 & 3 & 3 & 2 & 1 & 0 & 0 \\
\hline & Ascorbate & 8 & 6 & 4 & 2 & 1 & 0 & - & - & 0 \\
\hline & Mepacrine & 8 & 6 & 5 & 4 & 2 & 1 & 0 & - & 0 \\
\hline \multirow[t]{4}{*}{ Medium Dose $\mathrm{e}^{b}$} & None & 8 & 6 & 3 & 1 & 1 & 1 & 1 & 1 & 1 \\
\hline & NAC & 8 & 8 & 7 & 6 & 4 & 3 & 3 & 3 & 3 \\
\hline & Ascorbate & 8 & 5 & 4 & 2 & 2 & 1 & 0 & - & 0 \\
\hline & Mepacrine & 8 & 7 & 6 & 4 & 3 & 3 & 3 & 3 & 3 \\
\hline \multirow[t]{4}{*}{ Low dose $\mathrm{e}^{c}$} & None & 8 & 7 & 6 & 4 & 3 & 3 & 2 & 2 & 2 \\
\hline & NAC & 8 & 8 & 7 & 6 & 6 & 6 & 6 & 6 & 6 \\
\hline & Ascorbate & 8 & 6 & 5 & 5 & 4 & 4 & 3 & 3 & 3 \\
\hline & Mepacrine & 8 & 6 & 6 & 5 & 5 & 5 & 5 & 5 & 5 \\
\hline
\end{tabular}

Anthrax lethal toxin was administered to anesthetized animals in $300 \mu$ l sterile PBS via the tail vein. Antioxidants or mock were administered to animals in $200 \mu \mathrm{l}$ sterile PBS at the same time as toxin at a second tail vein site.

${ }^{a}$ LeTx $=100 \mu \mathrm{g} \mathrm{PA}+20 \mu \mathrm{g}$ LF per animal.

${ }^{b} \mathrm{LeTx}=50 \mu \mathrm{g}$ PA $+10 \mu \mathrm{g}$ LF per animal.

${ }^{c} \mathrm{LeTx}=50 \mu \mathrm{g}$ PA $+5 \mu \mathrm{g}$ LF per animal.

${ }^{d}$ Antioxidant dose $=800 \mathrm{mg}$ per animal.

${ }^{e}$ No deaths after day 14 .

\section{DISCUSSION}

While macrophages and other professional phagocytes generate reactive oxygen intermediates for microbicidal purposes, this potent defense mechanism constitutes a risk to the host itself. High concentrations of oxidants are known to modify vital residues in central homeostatic regulatory proteins (e.g., especially those involved in $\mathrm{Ca}^{++}$homeostasis) (24). Of the nucleophilic centers in proteins that are potential targets for oxidants, sulfhydryl ( $\mathrm{SH}$ ) groups are by far the most susceptible, and there is good evidence that modification of protein thiol groups can result in cell death. ROIs can also initiate a destructive peroxidative cascade that consumes a large percentage of plasma membrane lipids (24). Both classes of effects are disastrous to the cell.

Recently, circumstantial evidence from three different sources hinted that lysis of the macrophage by anthrax lethal toxin may involve the oxidative burst. First is the finding by Friedlander (10) that, although LeTx is fully capable of en- tering most cell types, cytotoxicity is apparently limited to $M \phi s$, a major producer of ROIs. No phenotype associated with intoxication has been presented for other cell types. Second, LeTxchallenged $M \phi s$ were found to undergo a cascade of cellular events that culminate in necrotic lysis (12). Those pathologies resemble, at least superficially, the ones seen with high concentrations of reactive oxidants. Third, anthrax toxin sequence data reveal no cysteines in the entire toxin complex, which includes three proteins totaling 2,278 amino acids (5). We therefore hypothesized an ROI link between LeTx actions and M $\phi$ lysis.

In support of this hypothesis, data presented here indicate that $M \phi$ s generate ROIs in response to LeTx challenge. The concentrations of superoxide anion produced in response to the toxin are two to three times higher than that induced by the potent stimulant PMA (Fig. la) or other known activators of the NADPH oxidase complex, such as LPS, $f$-met-leu-phe, or whole killed bacteria (data not shown). Kinetics of LeTx-in- 
duced lysis closely paralleled release of ROIs from cells (Fig. 1b), both beginning around 60-75 min. We also found that adding exogenous antioxidants to $M \phi$ s or boosting the endogenous $M \phi$ glutathione antioxidant system protected cells from the lethal effects of the toxin (Figs. 2 and 3), adding further support for the role of oxidants in cytolysis. Interestingly, since PMA alone did not induce cell death (Fig. 1b), it is possible that the greater ROI burden imposed by LeTx overloads the macrophage's innate capacity to protect itself from its own metabolites. It is also possible that LeTx misdirects ROI release to a cellular compartment that lacks endogenous antioxidants. Thus, if these oxidizing agents can be counteracted by experimental or therapeutic means before irreversible damage occurs, the cell survives. Finally, the finding that $\mathrm{M} \phi \mathrm{s}$ completely deficient in the ability to generate ROIs (both the murine line IC-2 1 and primary human monocytes from a patient with CGD; Table 2) are completely resistant to LeTx strongly implicates a central role for the NADPH oxidase complex and oxygen-related toxicities. It is somewhat surprising that the other major ROI-producing cell, the neutrophil, was found in earlier studies not to be lysed by the LeTx (25-26). It is possible that this cell's toxin resistance may be due to a block at an earlier step in the intoxication process. Alternatively, PMNs readily degranulate in response to many signals and it may be that LeTx directs secretion of ROIs in PMNs.

A more challenging question is whether toxin-induced ROI production plays an extended role in anthrax pathogenesis beyond bursting of the macrophage. It is now well established in other systems that sublytic concentrations of oxidants (e.g., $\mathrm{H}_{2} \mathrm{O}_{2}$ ) can modify gene expression patterns of immune cells (27). This gives rise to the hypothesis that ROIs act as second messengers in signal transduction pathways responsible for expression of host defense-oriented genes. For instance, NF- $\kappa \mathrm{B}$ is an inducible mediator of immune cell gene control $(27,28)$. In the resting immune cell, NF- $\kappa \mathrm{B}$ remains inactive in the cytoplasm, bound to an inhibitory protein called I $\kappa \mathrm{B}$, for inhibitor of $\kappa \mathrm{B}$. However, upon immune challenges that initiate the production of ROIs, NF- $\kappa \mathrm{B}$ dissociates from $\mathrm{I} \kappa \mathrm{B}$ and translocates to the nucleus, where it serves as a transcriptional activator of genes such as Ig $\kappa$, cytokines, MHC class I, HLA, serum amyloid A, $\beta_{2}$-microglobulin, HIV, and other viral genes (28). Antioxidants have been shown to inhibit this activation and to inhibit expression of genes under NF- $\kappa \mathrm{B}$ control
(27). Although the precise mechanism of oxidant-mediated NF- $\kappa$ B dissociation from $I \kappa B$ is unclear, it seems to be through action upon $I \kappa B$. It is theorized that ROIs could directly degrade or modify I $\kappa$ B by modifying susceptible Cys residues. Alternatively, a frequently observed effect of oxidant stress is the induction of proteolysis, especially by activation of metalloproteases, which could then degrade I $\kappa$ B. There are also reports of changes in phosphorylation states of $\mathrm{I} \kappa \mathrm{B}$ correlating with separation from NF- $\kappa \mathrm{B}$ in vitro. There have been even more indirect mechanisms proposed for NF- $\kappa \mathrm{B}$ activation.

The current study suggests that ROIs may have a regulatory role in $M \phi$ responses to LeTx, perhaps in a secondary messenger paradigm not unlike that seen with NF- $\kappa$ B. Data presented in Fig. 4 and Table 3 indicate that several classes of antioxidants inhibit LeTx-induced cytokine expression in vitro and protect, at least to some degree, against the cytokine-mediated shock pathologies seen in the toxin-challenged mouse. Why antioxidants did not entirely abolish LeTxinduced cytokine production is not yet known, but it may be that even if small amounts of oxidants escape neutralization a significant amplified response can occur. Additionally, antioxidants may have differing affinities to the various ROI species, some neutralizing the more damaging ones. Why all antioxidants did not protect animals equally may also involve pharmacological differences, such as delivery, subcellular localization, or breakdown rates of these agents.

It is interesting to speculate that the molecular target (as yet unknown) for LeTx action is involved, directly or indirectly, with metabolic regulation of the NADPH oxidase complex, and that stimulation of the oxidative burst can result in two tiers of phenomena: changes in $M \phi$ gene expression (low dose) and cytolysis (high dose). A dual role for ROIs in anthrax is consistent with a "dual-role" model for LeTx pathogenicity. At the onset of anthrax, small amounts of LeTx are released from the, as yet, few bacilli. These sublytic toxin doses would initiate a small or moderate ROI response in the susceptible $M \phi$, inducing them to express defense-related gene products (e.g., cytokines), but not compromising cellular integrity. We have shown previously that some of these products (e.g., IL-1 $\beta$ ) accumulate within the M $\phi$ cytoplasm during LeTx challenge (11). As the concentrations of toxin rise in the host, from bacterial counts approaching $10^{9} / \mathrm{ml}$ blood, lytic thresholds of LeTx (and therefore of ROIs) are reached, which may cause 
M $\phi$ s lysis. Newly formed inflammatory mediators may then be released suddenly into the circulation. This model could account for the dramatic "sudden-death" noted during anthrax infection.

In summary, the subversion of the phagocytic respiratory burst by LeTx represents a new class of virulence strategies for bacterial pathogens. For the bacillus, it seems a reasonable tactic to produce a toxin that incapacitates the major obstacle to proliferation. Additionally, as a pathogen in which no live animal-to-live animal transmission has been reported, killing of the host might help ensure evolutionary success. For the anthrax victim, the macrophage represents a paradox. First, at the cellular level, $M \phi$ s play a key role in both clearance of the invading bacillus as well as for generation of lethal, shockinducing cytokines. Second, at the metabolic level, oxidants account for the killing of most bacteria and for coordinating an aspect of host defense by acting as second messengers. But exaggerated production of unscavenged ROIs damages the integrity of the $M \phi$ with resultant release of inflammatory mediators into the tissues and blood stream. Although antioxidants, due to their ability to neutralize many LeTx actions, seem to hold potential as anthrax therapies, they may in fact compromise the phagocyte's overall abilities to kill bacteria via ROIs and therefore may be counter-productive in ameliorating the infection. Further knowledge is required to determine the best course of antibiotic, antitoxin, anticytokine, and antioxidant therapies needed to care for those people with anthrax.

\section{ACKNOWLEDGMENTS}

The authors would like to thank Marla Steinbeck, Kate Beauregard, and Jill Milne for critical discussion of this study and J.M. also for determination of cAMP values. This work was supported by NIH grants AI-22021, AI-22848 (RJC), AI-08649 (PCH), and AI-07118 (BRB). R.A.B.E. is an Established Investigator of the American Heart Association. B.A.K. is the recipient of a Charles A. Janeway, Child Health Research Scholarship.

\section{REFERENCES}

1. Koch R. (1881) Mitt. Kaiserliche Gesundheitsamte 1: 174-206.

2. Pasteur L. (1881) De l'attenuation des virus et de leur retour a la virulence. C. R. Acad. Sci. Agric. Bulg. 92: 429-435.

3. Metchnikoff E. (1905) Immunity in Infective Diseases. Cambridge University Press, London.

4. Stephen J. (1986) Anthrax toxin. In: Dorner F, Drews, J (eds). Pharmacology of Bacterial Toxins. Pergamon Press, Oxford, pp. 381-395.

5. Leppla SH. (1991) The anthrax toxin complex. In: Alouf J (ed). Sourcebook of Bacterial Protein Toxins. Academic Press, New York, pp. 277-302.

6. Leppla SH. (1984) Bacillus anthracis calmodulin-dependent adenylate cyclase: Chemical and enzymatic properties and interactions with eucaryotic cells. Adv. Cyclic. Nucleotide Prot. Phosphoryl. Res. 17: 189-198.

7. Klimpel KR, Arora N, Leppla SH. (1993) Anthrax toxin lethal factor has homology to the thermolysin-like proteases and displays protease activity. Abstracts, Amer. Soc. Microbiol. Annual Meeting 45 (abstract).

8. Cataldi A, Labruuyere E, Mock M. (1990) Construction and characterization of a protective antigen-deficient Bacillus anthracis strain. Mol. Microbiol. 4: 1111-1117.

9. Pezard C, Berche P, Mock M. (1991) Contribution of individual toxin components to virulence of Bacillus anthracis. Infect. Immun. 59: 3472-3477.

10. Friedlander AM. (1986) Macrophages are sensitive to anthrax lethal toxin through an acid-dependent process. J. Biol. Chem. 261: 7123-7126.

11. Hanna PC, Acosta D, Collier RJ. (1993) On the role of macrophages in anthrax. Proc. Natl. Acad. Sci. U.S.A. 90: 10198-10201.

12. Hanna PC, Kochi S, Collier RJ. (1992) Biochemical and physiological changes induced by anthrax lethal toxin in J774 macrophagelike cells. Mol. Biol. Cell 3: 1269-1277.

13. Leppla SH. (1988) Production and purification of anthrax toxin. Meth. Enzymol. 165: 103-116.

14. Tanaka Y, Kiyotaki C, Tanowitz H, and Bloom BR. (1982) Reconstitution of a varient macrophage cell line defective in oxygen metabolism with a $\mathrm{H}_{2} \mathrm{O}_{2}$-generating system. Proc. Natl. Acad. Sci. U.S.A. 79: 2584-2558.

15. Damiani G, Kiyotaki C, Soeller W, Sasada M, Peisach J, Bloom BR. (1980) Macrophage varients in oxygen metabolism. J. Exp. Med. 152: $803-822$. 
16. Johnston RBJ. (1984) Measurement of $\mathrm{O}_{2}{ }^{-}$ secreted by monocytes and macrophages. Meth. Enzymol. 105: 365-369.

17. Markert M, Andrews PC, Babior BM. (1994) Measurement of $\mathrm{O}_{2}$ - production by human neutrophils. The preparation and assay of NADPH oxidase-containing particles from human neutrophils. Meth. Enzymol. 105: 358-350.

18. Friedlander AM. (1990) The anthrax toxins. In: Saelinger CB (ed). Trafficking of Bacterial Toxins. CRC Press, Boca Raton, pp. 121-138.

19. (1989) In: Coenzymes and Cofactors, Vol III: Glutathione, Part A. Wiley Interscience, New York.

20. Griffith OW. (1981) Depletion of glutathione by inhibition of biosynthesis. Meth. Enzymol. 77: $59-63$.

21. Singh Y, Leppla SH, Bhatnagar R, and Friedlander AM. (1989) Internalization and processing of Bacillus anthracis lethal toxin by toxcin-sensitive and -resistant cells. J. Biol. Chem. 264: 11099-11102.

22. Scott P, James S, Sher A. (1985) The respiratory burst is not required for killing of intracellular and extracellular parasites by a lymphokine-activated macrophage cell line. Eur. J. Immunol. 15: 553-558.

23. Ezekowitz RAB. (1992) Cronic granulomatous disease: An update and a paradigm for the use of interferon-gamma as adjunct immunotherapy in infectious diseases. Current Top. Microbiol. Immunol. 181: 283-292.

24. Fawthrop DJ, Boobis AR, Davies DS. (1991) Mechanisms of cell death. Arch. Toxicol. 65: 437-444.

25. Wright GG, Mandell GL. (1986). Anthrax toxin blocks priming of neutrophils by lipopolysaccharide and by muramyl dipeptide. $J$. Exp. Med. 164: 1700-1709.

26. O'Brien J, Friedlander A, Dreier T, Ezzell J, Leppla S. (1985) Effect of anthrax toxin components on human neutrophils. Infect. Immunol. 46: 306-310.

27. Schreck R, Rieber P, Baeuerle PA. (1991) Reactive oxygen intermediates as apparently widely used messengers in the activation of the NF- $\kappa \mathrm{B}$ transcription factor and HIV-1. $E M B O$ J. 10: 2247-2258.

28. Lenardo MJ, Baltimore D. (1989) NF- $\kappa$ B: A pleiotropic mediator of inducable and tissuespecific gene control. Cell 58: 227-229. 